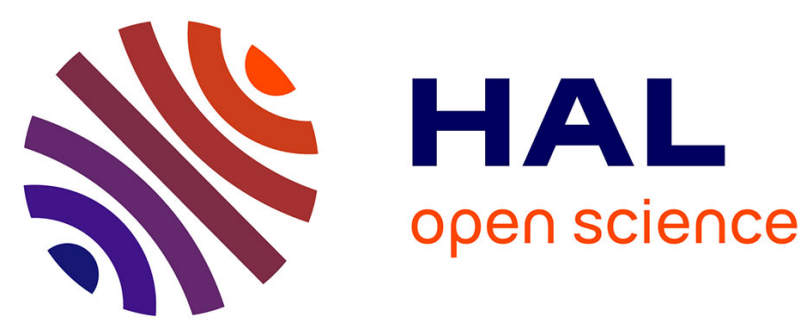

\title{
Impact of chemotherapy-induced menopause in women of childbearing age with non-metastatic breast cancer - Preliminary results from the MENOCOR study
}

Judith Passildas, Olivier Collard, Aude-Marie Savoye, Joyce Dohou, Angeline Ginzac, Emilie E. Thivat, Xavier X. Durando, Fabrice Kwiatkowski, Frédérique Penault-Llorca, Catherine Abrial, et al.

\section{To cite this version:}

Judith Passildas, Olivier Collard, Aude-Marie Savoye, Joyce Dohou, Angeline Ginzac, et al.. Impact of chemotherapy-induced menopause in women of childbearing age with non-metastatic breast cancer - Preliminary results from the MENOCOR study. Clinical Breast Cancer, 2018, 19 (1), pp.e74-e84. 10.1016/j.clbc.2018.10.003 . hal-01904507

\section{HAL Id: hal-01904507 https://hal.science/hal-01904507}

Submitted on 13 Nov 2019

HAL is a multi-disciplinary open access archive for the deposit and dissemination of scientific research documents, whether they are published or not. The documents may come from teaching and research institutions in France or abroad, or from public or private research centers.
L'archive ouverte pluridisciplinaire $\mathbf{H A L}$, est destinée au dépôt et à la diffusion de documents scientifiques de niveau recherche, publiés ou non, émanant des établissements d'enseignement et de recherche français ou étrangers, des laboratoires publics ou privés. 
Impact of chemotherapy-induced menopause in women of childbearing age with nonmetastatic breast cancer - Preliminary results from the MENOCOR study

MENOCOR study - An interim analysis

Judith Passildas ${ }^{1}$ (PhD student), Olivier Collard ${ }^{2}$ (MD), Aude-Marie Savoye ${ }^{3}$ (MD), Joyce Dohou $^{4}(\mathrm{PhD})$, Angeline Ginzac ${ }^{1}$ (PhD student), Emilie Thivat ${ }^{1}$ (PhD), Xavier Durando ${ }^{1}$ (MD, $\mathrm{PhD}$ ), Fabrice Kwiatkowski ${ }^{1}$ (MSc), Frédérique Penault-Llorca ${ }^{1}$ (MD, PhD), Catherine Abrial $^{1}(\mathrm{PhD})$, Marie-Ange Mouret-Reynier ${ }^{1}$ (MD).

1. Université Clermont Auvergne, Centre Jean Perrin, INSERM, U1240 Imagerie Moléculaire et Stratégies Théranostiques, F-63000 Clermont-Ferrand, France

2. Institut de Cancérologie de la Loire Lucien Neuwirth, 42270 Saint-Priest en Jarez, France

3. Institut Jean Godinot, 51726 Reims, France

4. Centre Hospitalier Universitaire de Poitiers, 86021 Poitiers, France

\section{Corresponding author:}

Judith PASSILDAS

CLCC Centre Jean Perrin

Division de Recherche Clinique

58, rue Montalembert, BP 392

63011 Clermont-Ferrand Cedex 1, FRANCE

Phone: +33.4.73.27.80.89

Fax:+33.4.73.27.84.10

e-mail: Judith.PASSILDAS@clermont.unicancer.fr 


\section{CONFLICT OF INTEREST}

We have no conflict of interest to disclose. 


\title{
MICRO-ABSTRACT
}

In our study, we evaluated the quality of life of young women experiencing chemotherapyinduced menopause. Our results underline that age and pre-treatment AMH level could be helpful to predict the menopause but these results have to be confirmed in further studies. At 6 months post-chemotherapy, the EORTC QLQ-BR23 questionnaire tended to highlight an impaired quality of life in menopaused patients.

\begin{abstract}
Background: Young breast cancer patients treated with chemotherapy can experience ovarian failure, which can lead to chemotherapy-induced menopause (CIM) impacting the quality of life (QoL). A prospective study was set out to evaluate the impact of CIM on QoL in women of childbearing age with non-metastatic breast cancer and this article reports results of the interim analysis conducted to evaluate feasibility and to see preliminary results.
\end{abstract}

Patients and Methods: 58 women (18-46 years) with newly-diagnosed breast cancer and treated with chemotherapy were eligible. QoL was assessed by self-administered questionnaires (QLQ-C30, QLQ-BR23 and Kupperman index) and hormonal variations (AMH, FSH and estradiol) were explored. We compared patients with $\geq 12$ months amenorrhea (CIM, $n=41)$ to patients with $<12$ months of amenorrhea (non-CIM, $n=17$ ).

Results: A good inclusion rate (4/month approx.) and sufficient data enabled us to perform this analysis. QLQ-C30 failed to show any difference between CIM and non-CIM patients $(\mathrm{p}=0.5)$. In contrast, at 6 months post-chemotherapy, CIM patients tended to have lower QoL as shown by QLQ-BR23 ( $\mathrm{p}=0.16)$ and more severe climacteric symptoms $(\mathrm{p}=0.01)$. Regarding hormonal variations, AMH pre-treatment level was higher in non-CIM patients $(p=0.0032)$. We also noted that CIM patients were older $(p=0.00013)$, had shorter menstruation cycle $(\mathrm{p}=0.082)$, and experienced faster amenorrhea $(\mathrm{p}=0.088)$.

Conclusions: The study is technically feasible and our preliminary results underline that age in association with pre-treatment AMH level could be helpful to predict ovarian function. QLQ-BR23 seemed to be stronger, more precise and appropriate to evaluate QoL changes in breast cancer patients than the QLQ-C30.

Key words: Breast cancer, young women, chemotherapy-induced menopause, quality of life, hormonal variations 


\section{TEXT}

\section{Introduction}

Breast cancer is the most common cancer among women, and about $12-20 \%$ of patients are in childbearing agepremenopausat. ${ }^{1-3}$ Young women with breast cancer are known to have the poorest prognosis due to the aggressiveness of the tumour, and they are mostly treated with chemotherapy. ${ }^{4,5}$ Despite the fact that chemotherapy improves survival and reduces the risk of recurrence ${ }^{6,7}$, it could cause ovarian failure leading to chemotherapy-induced amenorrhea (CIA) or premature menopause. ${ }^{1,8}$ Some studies reported the complexities in defining the natural menopause but it is even more difficult in the case of young women treated by chemotherapy. 9,10

According to the World Health Organization (WHO), menopause is characterized by at least one year of amenorrhea. ${ }^{11}$ Other definitions found in the literature vary considerably and describe menopause as a minimum of 1 to 2 years of amenorrhea. ${ }^{12,13}$ Hormonal changes are also considered for its definition. Among post-menopausal women, anti-mullerian hormone $(\mathrm{AMH})$ and estradiol serum levels decrease while follicle-stimulating hormone (FSH) serum level increases. ${ }^{14}$ Currently, AMH is considered to be a good marker of ovarian reserve ${ }^{15}$ and could play a role in the prediction of chemotherapy-induced menopause (CIM) in young cancer patients. ${ }^{16}$

Today, patient quality of life (QoL) is a central concern and an integral part of medical care. ${ }^{17-19}$ Some studies have documented impaired QoL in breast cancer survivors. In particular, young breast cancer patients are at greater risk of impaired health-related quality of life, including psychological disturbance, sexual problems or physical changes but very few studies have examined the specific case of women experiencing CIM. ${ }^{18,20-23}$ Moreover, the clear identification of menopause in patients treated by chemotherapy could be helpful to determine the appropriate endocrine therapy (eg. Tamoxifen or Aromatase Inhibitors) when hormone receptors are expressed. ${ }^{18,20,23}$

In order to clarify these issues, we conducted a prospective study (MENOCOR) on young women diagnosed with non-metastatic breast cancer. The primary endpoint is to assess the impact of CIM on the functional dimension of QoL using the European Organization for Research and Treatment of Cancer (EORTC) Quality of Life Questionnaire Core 30 (QLQC30) functional score. The secondary endpoints are hormonal variations (AMH, estradiol and FSH) and specific aspects of QoL based on menopausal status. An interim analysis of this study was performed to determine the feasibility of the study and see the preliminary results. 


\section{METHODS}

\section{Patients}

Eligible patients were women aged 18-45 years, with stage I-III breast cancer, without amenorrhea and scheduled for treatment with adjuvant or neoadjuvant chemotherapy. Age over 45 years, metastatic cancer, previous chemotherapy or hormonotherapy, hysterectomy or oophorectomy, and menopause were exclusion criteria. A total of 240 patients are expected to participate in this study and an interim analysis was scheduled after the inclusion of at least 60 patients with outcomes at 1.5 years follow-up, i.e. 12 months post-chemotherapy.

\section{Study design}

This is a prospective, multicenter study, approved by the CPP Sud Est VI Ethics Committee (08/11/2013) and registered at ClinicalTrials.gov (NCT02102568). A total of 63 patients were enrolled from April 2014 to June 2015 in the 3 participating centers: Jean Perrin Cancer Center (Clermont-Ferrand), Lucien Neuwirth Cancer Institute (Saint-Etienne) and Jean Godinot Cancer Institute (Reims). All patients provided informed consent.

After enrolment, patients were asked about their medical and gynaecological history. Breast cancer characteristics and physical activity were also recorded. Before chemotherapy, a complete biology report was drawn up for each patient according to the study provisions in order to ascertain the eligibility of the patient. The duration of patient participation in the trial is about 3 years with an average of 6 months chemotherapy and a follow-up of 2.5 years (Fig. 1).

\section{Study endpoints}

This interim analysis has been planned in order to evaluate the feasibility of the study: rhythm of inclusion, patients' responses and data collection. Preliminary results concerning the incidence of women with 12 months of amenorrhea, the primary endpoint, the Quality of Life Questionnaire - Breast 23 (QLQ-BR23) scores, vasomotor symptoms and their hormonal variations were evaluated for this interim analysis. It was conducted after the enrolment of 63 patients in the study, 1.5 years after inclusion, i.e. 12 months after chemotherapy. These results will be compared to data available at the end of the study and we will see if the 12 months of amenorrhea is predictive of menopause or not.

Because this study does not expose patients to a supplementary risk, this interim analysis will not request an interruption of inclusions.

\section{Menopausal status}

To identify the menopausal status of each patient at the end of the study and classify them into 2 groups - chemotherapy-induced menopause (CIM) and absence of chemotherapy-induced menopause (non-CIM) - information about their menstruation cycle was collected throughout the study and menopause was defined as $\geq 2$ years of amenorrhea. For this purpose, each patient was asked about the dates of her last menstruation before enrolment, before every 
chemotherapy cycle and at each follow-up, the time to onset of amenorrhea if present, the return of menstruation if applicable and the duration of amenorrhea. A calendar where patients noted their menstruation dates was issued at inclusion.

In order to perform the interim analysis conducted on data available at 1.5 years follow-up, 2 groups of patients were defined according to their amenorrhea duration and menopause is characterised by at least one year of amenorrhea as defined by the $\mathrm{WHO}^{11}$ : CIM with $\geq 12$ months of amenorrhea and non-CIM with $<12$ months of amenorrhea.

\section{Self-administered questionnaires}

To assess quality of life, patients were asked to complete the questionnaires several times during their participation in the study: at inclusion before chemotherapy (V0), at the end of chemotherapy (V1), 6 months (V2), 18 months (V3) and 30 months (V4) post-chemotherapy (Fig.1). In accordance with the study, this interim analysis focused on data available at inclusion, at the end of the treatment (approximately 6 months follow-up) and at 6 months post-chemotherapy (i.e. 1 year follow-up).

The primary outcome, i.e. the impact of CIM on functional QoL, was assessed using the QLQ-C30 functional score. ${ }^{24}$ The EORTC QLQ-C30 evaluates general QoL in oncology, it is divided into 3 scores: symptom, functional and global, and comprises a total of 30 items. The functional part of this questionnaire comprises 15 items divided into 5 dimensions: physical activity, daily activity, emotional status, cognition and social life. The total functional score is a percentage calculated by the average of all dimensions. In the STIC RMI study, ${ }^{25}$ menopaused women scored 5 points lower for the QLQ-C30 functional score compared to non-menopaused women, so the same difference was expected between our CIM and nonCIM patients after 2 years of amenorrhea. For this interim analysis, conducted only 6 months after chemotherapy, the differential of variation between the CIM and non-CIM groups is evaluated. A high score indicates good QoL. ${ }^{24}$

The EORTC QLQ-BR23 is used in combination with the EORTC QLQ-C30 and addresses specific issues of breast cancer. Like the QLQ-C30, it contains two dimensions, one for symptoms and the other one for functions with a total of 23 items scored from 1 to 4 . It particularly investigates body image, sexuality and pain. The total score is a percentage calculated by the average of all dimensions. In our study, a high score indicates good QoL. ${ }^{26}$

The Kupperman index is a specific questionnaire on climacteric symptoms. It contains 11 items with scores ranging from 0 to 3 . The global score is calculated by attributing a specific weight to each item, and can vary from 0 to 51. A higher score indicates more severe climacteric symptoms. ${ }^{27}$

Because of the large number of questionnaires used in this study, this interim analysis focused on the most relevant results.

\section{Hormones}

In order to study hormone variations (AMH, estradiol and FSH) for menopause prediction, measurements were conducted 2 times: before chemotherapy and one month after 
chemotherapy. Because no other hormonal dosages are waited for these patients, it allowed us to see the preliminary result for this interim analysis.

Concerning AMH, blood samples were collected and serum levels were measured by an external laboratory using electrochemiluminescence immunoassays on Roche Cobas 8000 . According to the laboratory, AMH is included between 0.7 and $52 \mathrm{pmol} / \mathrm{L}$ in women aged from 20 to 44 years; between 0.3 and $14.7 \mathrm{pmol} / \mathrm{L}$ in women aged from 45 to 50 years and is undetectable in menopausal women. The detection threshold was $0.21 \mathrm{pmol} / \mathrm{L}$ with a variation coefficient $<1.8 \%$.

Estradiol and FSH were measured in the hospital laboratory or in an ordinary analytical laboratory by chemiluminescence immunoassay. Estradiol and FSH in non-menopausal women are included between 79 and $1348 \mathrm{pmol} / \mathrm{L}$ and 1.7 to 17.5 , respectively. In menopausal women, estradiol is $<214 \mathrm{pmol} / \mathrm{L}$ and FSH is between 12.7 and 132.2 UI/L. The detection thresholds were $40 \mathrm{pmol} / \mathrm{L}$ and $0.2 \mathrm{UI} / \mathrm{L}$ respectively for estradiol and FSH.

\section{Statistical analysis}

Patient characteristics were described using standard distribution parameters: means \pm standard deviation and [range] for quantitative parameters (and median for non-Gaussian distributions), and counts and frequencies (\%) for categorical parameters. To study the evolution of questionnaire scores over time, a two-way ANOVA model (mixed model) was used. Statistical relationships between pairs of variables were explored using $\mathrm{Chi}^{2}$-tests for categorical parameters, t-tests or ANOVA when one parameter was quantitative (or the MannWhitney U-test or Kruskal-Wallis H-test in case of non-Gaussian distribution and/or heteroscedasticity), and with two quantitative parameters, Pearson's correlation coefficient (or for non-Gaussian distributions, Spearman's rank correlation). To compare the evolution of quantitative parameters before and after chemotherapy, the Student paired t-test was used. A multivariate analysis of factors influencing CIM was performed using a logistic regression model. All tests were two-sided. Significance was set at the standard $p$-value of $p \leq 0.05$. Data management and statistical calculations were performed on SEM software. ${ }^{28}$ 


\section{RESULTS}

\section{Patient characteristics}

A total of 63 patients were enrolled from April 2014 to June 2015. Among them, 5 were excluded from the interim analysis: 1 patient was wrongly included, another died during the study, for 2 patients there was too much missing data to perform the analysis and 1 patient withdrew her consent (Fig.2). A total of 58 patients were included in this interim analysis and their characteristics are shown in Table 1. The median age at enrolment was 40.8 [range 24.7 - 46]. Ninety-height percent of patients presented a grade II/III tumor and $21 \%$ were HER2 positive.

\section{Feasibility and recruitments}

A total of 63 patients were enrolled in 15 months, which means an average of 4 patients were newly included each month. The study expects a total of 240 patients which could be reached in approximately 5 years with the same inclusion rate. Of the 58 patients, $78 \%$ responded to questionnaires (Table 2) and 86\% got hormones measurements (Table 3). This amount of data was sufficient to enable the calculation of our first estimates.

\section{Menopausal status and chemotherapy-induced amenorrhea}

Among the 58 patients, only one patient did not develop CIA and had regular menstrual cycles. Among the other 57 patients, 41 patients (70.7\%) had at least 12 months of amenorrhea. Two groups of patients were defined on this basis: CIM $\geq 12$ months of amenorrhea $(n=41)$ and non-CIM $<12$ months of amenorrhea $(n=17)$ (Fig.2). Each group characteristics are shown in Table 1.

\section{Impact of CIM on quality of life}

The number of questionnaires per visit and per group is presented in Table 2.

\section{QLQ-C30 Functional score}

The QLQ-C30 functional score differed significantly in both patient groups between inclusion and 6 months post-chemotherapy $(\mathrm{p}=0.013)$. The score obtained at the end of chemotherapy was the lowest for both patient groups (CIM and non-CIM) and differed significantly from inclusion $(p=0.0056)$ and 6 months post-chemotherapy $(p=0.032)($ Fig.3a).

For the entire period (inclusion, end of chemotherapy and 6 months post-chemotherapy), no difference was evidenced between CIM and non-CIM patients $(\mathrm{p}=0.5)$. The percentage of variation between inclusion and 6 months post-chemotherapy was a 2\% decrease versus a 5\% for CIM and non-CIM patients respectively but this difference was not significant $(p=0.72)$. Concerning the mean score at 6 months post-chemotherapy, the functional score differed only by 2 points between CIM and non-CIM patients (77.7 versus 80.0; $\mathrm{p}=0.76$ ) (Fig. 3a). 
The QLQ-BR23 functional score: quality of life among breast cancer patients

As the QLQ-C30 functional score, the QLQ-BR23 functional score varied significantly in both patient groups between inclusion and 6 months post-chemotherapy $(p=0.0025)$. The score obtained at the end of chemotherapy was significantly lower from inclusion for the two groups of patients $(\mathrm{p}=0.00073)$. In contrast, difference between the end of chemotherapy and 6 months post-chemotherapy was not so clear $(p=0.12)($ Fig.3b).

Concerning the comparison of the two groups no difference was evidenced between them for the entire period (inclusion, end of chemotherapy and 6 months post-chemotherapy) $(\mathrm{p}=$ 0.33). Between inclusion and 6 months post-chemotherapy CIM patients had a 19\% decrease while non-CIM had a $3 \%$ decrease and this difference was leaning towards significance $(\mathrm{p}=$ $0.16)$. The comparison at 6 months post-chemotherapy reached near significance $(p=0.17)$ with a lower mean score for CIM patients and a difference of 13 points (44.43 versus 57.26) (Fig.3b).

The Kupperman Index: climateric symptoms

Between inclusion and 6 months post-chemotherapy, the Kupperman Index showed a clear time effect $\left(\mathrm{p}<10^{-7}\right)$ with an increase of the score at the end of chemotherapy (Fig.3c).

The comparison between CIM and non-CIM patients was close to being significant $(\mathrm{p}=$ 0.084). As expected, CIM patients had significantly higher Kupperman Index at 6 months post-chemotherapy $(\mathrm{p}=0.01)$ (Fig.3c). The specific dimension analysis at 6 months postchemotherapy showed nearly significant higher hot flushes and vaginal dryness in CIM patients than in non-CIM patients $(\mathrm{p}=0.096$ and $\mathrm{p}=0.091)$. Mood depression was also significantly higher in CIM patients ( $\mathrm{p}=0.025)$ (Fig. 3d).

\section{Hormones}

Hormone levels per group and per visit are presented in Table 3.

\section{$\underline{\mathrm{AMH} \text { variations }}$}

In each group, pre-treatment level of $\mathrm{AMH}$ was significantly higher from post-treatment level $\left(\mathrm{p}<10^{-7}\right)$ (Fig.4a).

By comparing the two groups of patients, it revealed that the variation of AMH level between inclusion and the end of chemotherapy was different, with a greater decrease in non-CIM patients $(p=0.0054)$. Of course, the pre-treatment level was significantly higher in non-CIM patients $(\mathrm{p}=0.0032)$ but no difference was evidence for the post-treatment level $(\mathrm{p}=0.26)$ (Fig.4a) (Table 3).

The analysis also showed a negative correlation between age and initial AMH - the older the patients were, the greater the decrease in AMH levels was $\left(r^{2}=0.38 ; p=1.10^{-6}\right)$ (Fig. $\left.4 b\right)$.

\section{$\underline{\text { FSH variations }}$}


Between enrolment and after chemotherapy, the FSH level increased significantly in both groups of patients $\left(\mathrm{p}<10^{-7}\right)$ (data not shown).

No difference was observed between CIM and non-CIM patients for the variation of FSH level between these 2 periods $(\mathrm{p}=0.25$ ). The difference between CIM and non-CIM patients was nearly significant for the pre-treatment level of FSH (10 UI/L versus $5 \mathrm{UI} / \mathrm{L} ; \mathrm{p}=0.07)$ with a higher level in CIM patients but it was not the case of the post-treatment level $(\mathrm{p}=$ 0.47) (data not shown) (Table 3).

\section{$\underline{\text { Estradiol levels }}$}

All patients saw their serum estradiol levels fall markedly between inclusion and the end of the treatment $(\mathrm{p}=0.000014)$ (data not shown).

No difference was evidenced between CIM and non-CIM patients for the estradiol level before chemotherapy $(\mathrm{p}=0.49)$, after chemotherapy $(\mathrm{p}=0.94)$ or for the variation between these 2 times $(\mathrm{p}=0.36)$ (data not shown) (Table 3 ).

\section{Risk factors for CIM patients (univariate analysis)}

The comparison of other characteristics between CIM and non-CIM groups showed that CIM patients were 9 years older (43 versus $34 ; \mathrm{p}=0.00013)$, had done less fertility preservation $(\mathrm{p}=$ $0.03)$, had a tendency to have shorter menstruations cycles $(\mathrm{p}=0.082)$ and earlier onset of amenorrhea during chemotherapy (no. of chemotherapy cycles before amenorrhea 3 versus 4; $\mathrm{p}=0.088)($ Table1).

\section{Multivariate analysis}

On multivariate analysis only age was associated with menstrual status $(\mathrm{p}=0.000022)$, older patients have greater risk to experience premature menopause. 


\section{DISCUSSION}

In this prospective multicenter study, we conducted an interim analysis on data available at 1.5 years follow-up, i.e. 12 months post-chemotherapy, to see the feasibility and the preliminary results of the study.

A total of 63 patients have been enrolled in 15 months showing a good inclusion rate and that the recruitment of the other 177 patients is technically feasible. Moreover the response rate $(\approx$ $80 \%$ ) of questionnaires and the hormones measurements were sufficient to perform this analysis and allow us to pursue this study. A particular attention should be given to questionnaires to limit the missing data in upcoming visits and patients.

In order to see the preliminary results of this study, we compared patients presenting at least 12 months of amenorrhea (CIM) to patients without amenorrhoea or with less than 12 months of amenorrhea (non-CIM). In this analysis, among our 58 patients, $98.3 \%$ of the patients experienced chemotherapy induced amenorrhea (CIA) and $70.7 \%$ had long term amenorrhea (or CIM) lasting at least 12 months. The incidence of CIM seems to be higher than the incidence found in the literature which could be explained by the chemotherapy regimen. ${ }^{29,30}$ In fact, $71.1 \%$ of our patients received chemotherapy with FEC (5fluorouracile, epirubicin and cyclophosphamide) and Berlière et al. found approximately the same incidence of long term amenorrhea with FEC-based chemotherapy. ${ }^{31}$

In line with previous studies, age was the main risk factor of CIM, older women have higher risk to become menopaused. ${ }^{30,32,33}$ According to Wallace and Kesley, ovarian reserve declines with age and only $3 \%$ remains at age 40 . Therefore, among older patients, the risk of long term amenorrhea or early menopause is greater. ${ }^{34}$ This could explain the longer duration of amenorrhea for CIM women and these results are consistent with findings by Peterk et al. which showed that: "older age is strongly related to decreased menstrual bleeding" in natural menopause as in chemotherapy-related premature menopause. ${ }^{35}$

However the global fertility preservation rate was not important (12\%), it was higher in nonCIM than CIM patients which could be explained by their younger age. Of course, younger women could be more interested in future pregnancy and as a consequence they could be more worried about pregnancy problems than older women. In contrast, our study underlines that younger women recover more often menstruations and are less at risk of premature menopause so fertility preservation should be ideally discussed with elder patients (over 40) desiring to have children. ${ }^{36}$

In our analysis, CIM patients seemed to have shorter menstruation cycles than non-CIM patients. Apart from studies defining the menopause, the association between short menstruation cycles and menopause was not previously evidenced in breast cancer patients treated by chemotherapy. ${ }^{11,37}$ As defined by the WHO in $1996^{11}$, the length of menstrual cycle became shorter when women are closer to menopause; we can deduce that this information could be also predictive of menopause in our patients.

Concerning the number of chemotherapy cycles, non-CIM patients received on average 1 more chemotherapy cycle before the onset of amenorrhea, which means that amenorrhea appeared later in younger women as shown by Bines et al. ${ }^{38}$ This earlier onset of amenorrhea 
could be explained by a diminished stock of ovarian follicles in older women, in this case the CIM patients. ${ }^{35}$ According to our results, older age, short menstruation cycle and faster amenorrhea could be predictive factors of longer CIA or premature menopause in young breast cancer patients treated by chemotherapy.

The quality of life assessment focused on functional part (QLQ-C30 and QLQ-BR23) and climacteric symptoms (Kupperman index). It showed significantly impaired QoL shortly after chemotherapy in both groups of patients. This time effect concerned the 3 questionnaires (QLQ-C30, QLQ-BR23, and the Kupperman index) showing that chemotherapy was damaging for the patients' QoL. These results are consistent with other studies and reviews demonstrating the negative effect of chemotherapy or other anticancer treatments on patients' QoL. ${ }^{39-41}$ Scores obtained at 6 months post-chemotherapy on the QLQ-C30 and QLQ-BR23 measures however exhibit a tendency to return to baseline levels, showing that many consequences of chemotherapy on QoL were reversible and lasted only for a short period of time. ${ }^{41}$ Before and/or after chemotherapy, all patients underwent other anticancer treatments such as surgery, radiotherapy and hormonotherapy which could also impact the patients QoL. Despite this, QoL scores were lower at the end of chemotherapy suggesting that chemotherapy should have more negative impact than other treatments.

Concerning the main objective (QLQ-C30 functional score), which evaluates the functional part of general QoL in cancer patients; no difference was evidenced between CIM and nonCIM patients. The score variation was quite similar showing that the functional part of general QoL was not affected by the CIM. This preliminary data failed to reach the same difference as the STIC RMI study (5 points lesser in menopaused women). In contrast, between inclusion and 6 months post-chemotherapy, the functional score of QLQ-BR23 decreased stronger in CIM patients than in non-CIM patients showing an impaired QoL. A difference of 13 points was also reported between them at 6 months post-chemotherapy, so the difference of 5 points was reached for this questionnaire. Even though these results did not reach significance, they underline a negative impact of menopause or CIM on patients QoL. QLQ-BR23 questionnaire addresses specific issues of breast cancer such as body image and sexuality whereas QLQC30 is more general. The QLQ-BR23 seemed to be more precise and more adequate to evaluate the patients' QoL in particular in our study. At this point of the study, we cannot conclude on the real incidence of CIM or its effect on functional QoL, but the results showed that long-term chemotherapy-induced amenorrhea has a tendency, with time, to damage the functional dimension of patients' QoL measured by the QLQ-BR23. We can expect that with the inclusion of the next 177 patients and a longer follow-up (30 months post-chemotherapy), differences will reach significance and we will be able to confirm our hypotheses. The Kupperman index evaluates the climacteric symptoms. At the end of chemotherapy, all patients experienced increase of these symptoms but only CIM patients continuously reported the symptoms at 6 months post-chemotherapy. CIM negatively impacted the patients' mood, hot flushes and vaginal dryness. The Kupperman index confirmed that CIM patients were closer to postmenopausal status than non-CIM patients and the differentiation based on amenorrhea duration seems to be a good marker.

Concerning hormonal variations, our data showed that the overall serum AMH and estradiol levels decreased after chemotherapy, whereas serum FSH levels increased, confirming the cytotoxic effect of chemotherapy on ovarian function. ${ }^{8,11,41}$ As in other studies, a marked difference for AMH and FSH levels between inclusion and the end of chemotherapy was shown, but in our study this difference was also significant for estradiol. ${ }^{41-43}$ The comparison of these previous studies with our data showed that the numbers of patients included was 
smaller than in our study: the greater power here could explain why the difference reached significance for estradiol variations.

The initial AMH serum level was different between the 2 groups of patients with a higher level in non-CIM patients: this shows that low pre-treatment AMH level is linked to longterm amenorrhea. ${ }^{43}$ In contrast, the level after chemotherapy was mainly under the detection threshold for both groups of patients without any difference between them. As shown by other previous studies, the AMH level at the end of chemotherapy is at its lowest and many patients has an undetectable level, which is consistent with our data. ${ }^{42-44}$ Concerning AMH serum variation between inclusion and the end of chemotherapy, a significant difference was shown between the 2 groups with a greater decrease among younger patients, which can be attributed to the difference found at baseline. On the other hand, a strong correlation between age and initial AMH level was evidenced, which correlates with the high level of AMH in non-CIM patients (younger patients). As shown by Anders et al. and Henry et al., this data suggests that the initial AMH serum level, in association with age, may play a role in the prediction of ovarian function. ${ }^{43,45}$ Although the prediction of CIM could help to determine the appropriate endocrine therapy when needed, further studies with larger cohort are needed to confirm these results. The final analysis of our study (with a total of 240 patients) will be much more informative on this issue. In addition, initial FSH level tended to differ between CIM and nonCIM patients with a high level in CIM patients. Basal FSH level could also contribute to predict CIM on young patients.

\section{$\underline{\text { Limitations }}$}

This interim analysis has some limitations, especially the small power due to a small sample size. Concerning AMH, it would have been more interesting to continue the measurements during the follow-up but we could not do this because of the considerable cost. Another limitation we should mention is the absence of transvaginal ultrasound performed before and after chemotherapy which would have strengthened the data about the ovarian reserve with the ovarian volume calculation and the antra follicles count. 


\section{CONCLUSION}

This analysis suggests that the study is technically feasible with a good inclusion rate and sufficient data. Preliminary results did not evidence any difference between CIM and nonCIM patients for our main objective (impact of CIM on functional score of QLQ-C30). In contrast, we were able to point out that CIM patients specific QoL (evaluated by the QLQBR23) is more impacted than non-CIM patients and they experienced more climacteric symptoms as expected. According to this result, QLQ-BR23 seems to be more appropriate to evaluate the young breast cancer patients QoL changes. Our results also underline that amenorrhea $\geq 12$ months is linked to certain parameters: older age, low baseline AMH, high baseline FSH, shorter menstruation cycles and earlier onset of amenorrhea. In particular, initial AMH level seems to be more informative regarding the risk of CIM when compared to FSH and/or estradiol. But, these data are still insufficient to determine pre-treatment AMH level as a predictive factor of CIM and additional prospective studies are needed on this issue. We also expect the final analysis with more patients (240 planned) and a longer follow-up (30 months post-chemotherapy) to be more precise on issues we have discussed about. 


\section{CLINICAL PRACTICE POINTS}

- Menopausal status is difficult to predict in young breast cancer patients treated by chemotherapy. Moreover, chemotherapy is known to impair the patients' quality of life but the specific case of young women experiencing chemotherapy-induced menopause lacks of knowledge.

- Our preliminary results suggest, as expected, that age is predictive of menopause. Other parameters like pre-treatment AMH level, in association with pre-treatment FSH level, shorter menstruation cycle and earlier amenorrhea seem also to be predictive of menopause in young women treated by chemotherapy. Additional prospective studies are needed to confirm these results. The EORTC QLQ-BR23 seems to be more precise to evaluate the quality of life than the EORTC QLQ-C30 and it tends to show an impaired quality of life in menopaused patients (at 6 months post-chemotherapy) which have to be confirmed in a larger cohort.

- Clearly identifying menopausal status of young breast cancer patients could be helpful to determine the appropriate treatment, especially hormone therapy. Concerning the quality of life, supportive care could be given to young patients experiencing CIM in order to improve their quality of life. 


\section{ACKNOWLEDGMENTS}

This study was supported by La Ligue régionale contre le Cancer and La Clermontoise. We are thankful to them for giving their financial support which enables us to conduct this project. 


\section{REFERENCES}

1. Liebens F, Carly B, Pastijn A, Fastrez M, Vandromme J. Desire for a Child and Breast Cancer. Acta Chirurgica Belgica. 2008;108(1):83-87. doi:10.1080/00015458.2008.11680181

2. GLOBOCAN 2012 age-specific table. http://globocan.iarc.fr/old/agespecific_table_r.asp?selection $=224900 \&$ title $=$ World \&sex $=2 \&$ type $=0 \&$ stat $=0 \&$ window $=1 \&$ sort $=$ 0\&submit=\%C2\%A0Execute\%C2\%A0. Accessed October 17, 2017.

3. Ferlay J, Steliarova-Foucher E, Lortet-Tieulent J, et al. Cancer incidence and mortality patterns in Europe: Estimates for 40 countries in 2012. European Journal of Cancer. 2013;49(6):13741403. doi:10.1016/j.ejca.2012.12.027

4. Kroman N, Tutt A, Jensen M-B, et al. Factors influencing the effect of age on prognosis in breast cancer: population based studyCommentary: much still to learn about relations between tumour biology, prognosis, and treatment outcome in early breast cancer. BMJ. 2000;320(7233):474-479. doi:10.1136/bmj.320.7233.474

5. Gajdos C, Tartter PI, Bleiweiss IJ, Bodian C, Brower ST. Stage 0 to stage III breast cancer in young women11No competing interests declared. Journal of the American College of Surgeons. 2000;190(5):523-529. doi:10.1016/S1072-7515(00)00257-X

6. Villarreal-Garza C, Bargallo-Rocha JE, Soto-Perez-de-Celis E, et al. Real-world outcomes in young women with breast cancer treated with neoadjuvant chemotherapy. Breast Cancer Res Treat. 2016;157(2):385-394. doi:10.1007/s10549-016-3811-2

7. Early Breast Cancer Trialists' Collaborative Group (EBCTCG). Effects of chemotherapy and hormonal therapy for early breast cancer on recurrence and 15-year survival: an overview of the randomised trials. Lancet. 2005;365(9472):1687-1717. doi:10.1016/\$0140-6736(05)66544-0

8. Anderson RA, Themmen APN, -Qahtani AA, Groome NP, Cameron DA. The effects of chemotherapy and long-term gonadotrophin suppression on the ovarian reserve in premenopausal women with breast cancer. Hum Reprod. 2006;21(10):2583-2592. doi:10.1093/humrep/del201

9. Gracia CR, Sammel MD, Freeman EW, et al. Defining menopause status: creation of a new definition to identify the early changes of the menopausal transition. Menopause. 2005;12(2):128-135.

10. Phipps Al, Ichikawa L, Bowles EJA, et al. Defining Menopausal Status in Epidemiologic Studies: A Comparison of Multiple Approaches and their Effects on Breast Cancer Rates. Maturitas. 2010;67(1):60-66. doi:10.1016/j.maturitas.2010.04.015

11. WHO Scientific Group on Research on the Menopause in the 1990s (1994 : Geneva S, Organization WH. Research on the menopause in the 1990s : report of a WHO scientific group. Recherche sur la ménopause : bilan de la décennie : rapport d' un groupe scientifique de l' OMS. 1996. http://www.who.int/iris/handle/10665/41841. Accessed October 17, 2017.

12. Boccardo F, Rubagotti A, Amoroso D, et al. Chemotherapy versus tamoxifen versus chemotherapy plus tamoxifen in node-positive, oestrogen-receptor positive breast cancer patients. An update at 7 years of the 1st GROCTA (breast cancer adjuvant chemo-hormone 
therapy cooperative group) trial. European Journal of Cancer. 1992;28(2):673-680.

doi:10.1016/S0959-8049(05)80123-6

13. Clemons $M$, Simmons $C$. Identifying menopause in breast cancer patients: considerations and implications. Breast Cancer Res Treat. 2007;104(2):115-120. doi:10.1007/s10549-006-9401-y

14. Murthy V, Chamberlain RS. Menopausal symptoms in young survivors of breast cancer: a growing problem without an ideal solution. Cancer Control. 2012;19(4):317-329.

15. Hansen KR, Hodnett GM, Knowlton N, Craig LB. Correlation of ovarian reserve tests with histologically determined primordial follicle number. Fertility and Sterility. 2011;95(1):170-175. doi:10.1016/j.fertnstert.2010.04.006

16. Trapp E, Steidl J, Rack B, et al. Anti-Müllerian hormone (AMH) levels in premenopausal breast cancer patients treated with taxane-based adjuvant chemotherapy - A translational research project of the SUCCESS A study. The Breast. 2017;35(Supplement C):130-135. doi:10.1016/j.breast.2017.07.007

17. Spitzer WO. State of science 1986: Quality of life and functional status as target variables for research. Journal of Chronic Diseases. 1987;40(6):465-471. doi:10.1016/0021-9681(87)90002-6

18. Wiklund I. Methods of assessing the impact of climacteric complaints on quality of life. Maturitas. 1998;29(1):41-50. doi:10.1016/S0378-5122(98)00027-9

19. Schmidt ME, Wiskemann J, Steindorf K. Quality of life, problems, and needs of disease-free breast cancer survivors 5 years after diagnosis. Qual Life Res. May 2018:1-10. doi:10.1007/s11136-018-1866-8

20. Ganz PA, Greendale GA, Petersen L, Kahn B, Bower JE. Breast Cancer in Younger Women: Reproductive and Late Health Effects of Treatment. JCO. 2003;21(22):4184-4193. doi:10.1200/JCO.2003.04.196

21. Avis NE, Assmann SF, Kravitz HM, Ganz PA, Ory M. Quality of Life in Diverse Groups of Midlife Women: Assessing the Influence of Menopause, Health Status and Psychosocial and Demographic Factors. Qual Life Res. 2004;13(5):933-946. doi:10.1023/B:QURE.0000025582.91310.9f

22. Safarinejad MR, Shafiei N, Safarinejad S. Quality of life and sexual functioning in young women with early-stage breast cancer 1 year after lumpectomy. Psycho-Oncology. 2013;22(6):12421248. doi:10.1002/pon.3130

23. Vanlemmens L, Fournier E, Boinon D, Machavoine J-L, Christophe V. Qualité de vie des femmes jeunes ayant un cancer du sein localisé et de leur partenaire : nécessité de développement de questionnaires spécifiques pour la patiente et le partenaire. Bulletin du Cancer. 2012;99(6):685691. doi:10.1684/bdc.2012.1598

24. Aaronson N, Ahmedzai S, Bergman B, et al. The European-Organization-For-Research-AndTreatment-Of-Cancer QLQ-C30 - A Quality-Of-Life Instrument for Use in International ClinicalTrials in Oncology. Journal of the National Cancer Institute. 1993;85:365-376. doi:10.1093/jnci/85.5.365 
25. Dauplat J, Kwiatkowski F, Rouanet $P$, et al. Quality of life after mastectomy with or without immediate breast reconstruction. Br J Surg. 2017;104(9):1197-1206. doi:10.1002/bjs.10537

26. Sprangers MA, Groenvold M, Arraras JI, et al. The European Organization for Research and Treatment of Cancer breast cancer-specific quality-of-life questionnaire module: first results from a three-country field study. JCO. 1996;14(10):2756-2768. doi:10.1200/JCO.1996.14.10.2756

27. Heinemann LA, Potthoff $P$, Schneider HP. International versions of the Menopause Rating Scale (MRS). Health Qual Life Outcomes. 2003;1:28. doi:10.1186/1477-7525-1-28

28. Kwiatkowski F, Girard M, Hacene K, Berlie J. Sem : un outil de gestion informatique et statistique adapté à la recherche en cancérologie. Bulletin du Cancer. 2000;87(10):715-721.

29. Torino F, Barnabei A, De Vecchis L, et al. Chemotherapy-induced ovarian toxicity in patients affected by endocrine-responsive early breast cancer. Critical Reviews in Oncology/Hematology. 2014;89(1):27-42. doi:10.1016/j.critrevonc.2013.07.007

30. Parulekar WR, Day AG, Ottaway JA, et al. Incidence and prognostic impact of amenorrhea during adjuvant therapy in high-risk premenopausal breast cancer: analysis of a National Cancer Institute of Canada Clinical Trials Group Study--NCIC CTG MA.5. J Clin Oncol. 2005;23(25):60026008. doi:10.1200/JCO.2005.07.096

31. Berliere $M$, Dalenc F, Malingret N, et al. Incidence of reversible amenorrhea in women with breast cancer undergoing adjuvant anthracycline-based chemotherapy with or without docetaxel. BMC Cancer. 2008;8:56. doi:10.1186/1471-2407-8-56

32. Fornier MN, Modi S, Panageas KS, Norton L, Hudis C. Incidence of chemotherapy-induced, longterm amenorrhea in patients with breast carcinoma age 40 years and younger after adjuvant anthracycline and taxane. Cancer. 2005;104(8):1575-1579. doi:10.1002/cncr.21385

33. Liem GS, Mo FKF, Pang E, et al. Chemotherapy-Related Amenorrhea and Menopause in Young Chinese Breast Cancer Patients: Analysis on Incidence, Risk Factors and Serum Hormone Profiles. PLOS ONE. 2015;10(10):e0140842. doi:10.1371/journal.pone.0140842

34. Wallace WHB, Kelsey TW. Human Ovarian Reserve from Conception to the Menopause. PLOS ONE. 2010;5(1):e8772. doi:10.1371/journal.pone.0008772

35. Petrek JA, Naughton MJ, Case LD, et al. Incidence, Time Course, and Determinants of Menstrual Bleeding After Breast Cancer Treatment: A Prospective Study. JCO. 2006;24(7):1045-1051. doi:10.1200/JCO.2005.03.3969

36. Ajala T, Rafi J, Larsen-Disney P, Howell R. Fertility Preservation for Cancer Patients: A Review. Obstet Gynecol Int. 2010;2010. doi:10.1155/2010/160386

37. Greendale GA, Lee NP, Arriola ER. The menopause. The Lancet. 1999;353(9152):571-580. doi:10.1016/S0140-6736(98)05352-5

38. Bines J, Oleske DM, Cobleigh MA. Ovarian function in premenopausal women treated with adjuvant chemotherapy for breast cancer. JCO. 1996;14(5):1718-1729.

doi:10.1200/JCO.1996.14.5.1718 
39. Howard-Anderson J, Ganz PA, Bower JE, Stanton AL. Quality of Life, Fertility Concerns, and Behavioral Health Outcomes in Younger Breast Cancer Survivors: A Systematic Review. J Natl Cancer Inst. 2012;104(5):386-405. doi:10.1093/jnci/djr541

40. Kroenke CH, Rosner B, Chen WY, Kawachi I, Colditz GA, Holmes MD. Functional Impact of Breast Cancer by Age at Diagnosis. JCO. 2004;22(10):1849-1856. doi:10.1200/JCO.2004.04.173

41. Wenners A, Grambach J, Koss J, et al. Reduced ovarian reserve in young early breast cancer patients: preliminary data from a prospective cohort trial. BMC Cancer. 2017;17. doi:10.1186/s12885-017-3593-x

42. Anderson RA, Mansi J, Coleman RE, Adamson DJA, Leonard RCF. The utility of anti-Müllerian hormone in the diagnosis and prediction of loss of ovarian function following chemotherapy for early breast cancer. European Journal of Cancer. 2017;87(Supplement C):58-64. doi:10.1016/j.ejca.2017.10.001

43. Henry NL, Xia R, Schott AF, McConnell D, Banerjee M, Hayes DF. Prediction of Postchemotherapy Ovarian Function Using Markers of Ovarian Reserve. The Oncologist. 2014;19(1):68-74. doi:10.1634/theoncologist.2013-0145

44. Dezellus A, Barriere $P$, Campone $M$, et al. Prospective evaluation of serum anti-Müllerian hormone dynamics in 250 women of reproductive age treated with chemotherapy for breast cancer. European Journal of Cancer. 2017;79(Supplement C):72-80. doi:10.1016/j.ejca.2017.03.035

45. Anderson RA, Cameron DA. Pretreatment Serum Anti-Müllerian Hormone Predicts Long-Term Ovarian Function and Bone Mass after Chemotherapy for Early Breast Cancer. J Clin Endocrinol Metab. 2011;96(5):1336-1343. doi:10.1210/jc.2010-2582 


\section{TABLES CAPTIONS}

\section{Table 1: Patient characteristics}

${ }^{1}$ One patient was 46 years old. She was included with the agreement of the study coordinator.

“*” indicates a significant difference $(p \leq 0.05)$ between CIM and non-CIM patients.

\begin{tabular}{|c|c|c|c|c|c|}
\hline & \multicolumn{2}{|c|}{ CIM and non-CIM } & CIM & Non-CIM & $P$ value \\
\hline Characteristics & $\mathbf{N}$ & $\%$ & $\mathbf{N}$ & $\mathbf{N}$ & \\
\hline No. patients & 58 & 100 & 41 & 17 & - \\
\hline $\begin{array}{l}\text { Median age at enrolment } \\
\text { (years) [range] }\end{array}$ & $40.8[24.7-46]^{1}$ & - & $42.5[33.3-46]$ & $33.8[24.7-44.1]$ & $* 0.00013$ \\
\hline $\begin{array}{l}\text { Median Body Mass Index } \\
\left(\mathrm{kg} / \mathrm{m}^{2}\right) \text { [range] }\end{array}$ & $22[18-44]$ & - & $22[18-44]$ & 22 |18-34] & 0.21 \\
\hline Underweight $(<18.5)$ & 4 & 7 & 2 & 2 & 1.00 \\
\hline Normal $(18.5-24.9)$ & 35 & 60 & 23 & 12 & 0.67 \\
\hline Overweight $(25-29.9)$ & 9 & 16 & 8 & 1 & 0.70 \\
\hline Obese $(\geq 30)$ & 10 & 17 & 8 & 2 & 1.00 \\
\hline Performance status & - & - & - & - & 0.79 \\
\hline 0 & 51 & 88 & 37 & 14 & - \\
\hline 1 & 4 & 7 & 2 & 2 & - \\
\hline 2 & 1 & 2 & 1 & 0 & - \\
\hline Unknown & 2 & 3 & 1 & 1 & - \\
\hline $\begin{array}{l}\text { Children before } \\
\text { chemotherapy }\end{array}$ & - & - & - & - & 0.48 \\
\hline No & 7 & 12 & 4 & 3 & - \\
\hline$\geq 1$ & 51 & 88 & 37 & 14 & - \\
\hline Fertility preservation & 7 & 12 & 2 & 5 & $* 0.03$ \\
\hline Smoking status & - & - & - & - & 0.19 \\
\hline Current & 14 & 24 & 11 & 3 & - \\
\hline Former & 16 & 28 & 13 & 3 & - \\
\hline Never & 26 & 45 & 16 & 10 & - \\
\hline $\begin{array}{l}\text { Breast cancer family } \\
\text { history }\end{array}$ & 30 & 52 & 20 & 10 & 0.48 \\
\hline Histological type & - & - & - & - & 0.30 \\
\hline
\end{tabular}




\begin{tabular}{|c|c|c|c|c|c|}
\hline Invasive ductal carcinoma & 45 & 77.6 & 31 & 14 & - \\
\hline Invasive lobular carcinoma & 5 & 8.6 & 5 & 0 & - \\
\hline Others & 8 & 13.8 & 5 & 3 & - \\
\hline Histologic grade & - & - & - & - & 0.65 \\
\hline 1 & 1 & 2 & 1 & 0 & - \\
\hline II/III & 57 & 98 & 40 & 17 & - \\
\hline Nodal status & - & - & - & - & 0.27 \\
\hline Positive & 27 & 47 & 21 & 6 & - \\
\hline Negative & 31 & 53 & 20 & 11 & - \\
\hline Hormonal receptors & - & - & - & - & - \\
\hline Estrogen-positive & 43 & 74 & 30 & 13 & 0.77 \\
\hline Progesterone-positive & 32 & 55 & 23 & 9 & 0.99 \\
\hline HER-positive & 12 & 21 & 8 & 4 & 0.7 \\
\hline $\begin{array}{l}\text { Neo-adjuvant } \\
\text { chemotherapy }\end{array}$ & 30 & 52 & 21 & 9 & 0.9 \\
\hline Chemotherapy regimens & - & - & - & - & 0.29 \\
\hline 3FEC +3 Taxotere & 31 & 52.5 & 22 & 9 & - \\
\hline 4FEC + 4 Taxotere & 11 & 18.6 & 9 & 2 & - \\
\hline GTAC & 8 & 13.6 & 5 & 3 & - \\
\hline $4 A C+4 T$ & 6 & 10.2 & 5 & 1 & - \\
\hline 4TAC & 1 & 1.7 & 0 & 1 & - \\
\hline $\mathrm{TCH}$ & 1 & 1.7 & 0 & 1 & - \\
\hline
\end{tabular}

Abbreviations:

AC: doxorubicin and cyclophosphamide; FEC: 5fluorouracile, epirubicin and cyclophosphamide; SBR: $\mathrm{T}$ : docetaxel (or paclitaxel); TAC: docetaxel, adriamycin and cyclophosphamide; $\mathrm{TCH}=$ docetaxel (or paclitaxel), carboplatin and Herceptin 
Table 2: Number of questionnaires per group and per visit

\begin{tabular}{ccccccc}
\hline $\begin{array}{c}\text { No. of } \\
\text { questionnaires }\end{array}$ & \multicolumn{2}{c}{ Inclusion (V0) } & $\begin{array}{c}\text { End of chemotherapy } \\
\text { (V1) }\end{array}$ & \multicolumn{2}{c}{$\begin{array}{c}\text { 6 months post- } \\
\text { chemotherapy (V2) }\end{array}$} \\
\hline $\begin{array}{c}\text { CIM } \\
\begin{array}{c}\text { QLQ-C30 functional } \\
\text { score }\end{array}\end{array}$ & 38 & 17 & 34 & 14 & 30 & 14 \\
$\begin{array}{c}\text { QLQ-BR23 } \\
\text { functional score }\end{array}$ & 38 & 17 & 34 & 14 & 30 & 14 \\
\hline $\begin{array}{c}\text { Kupperman index } \\
\text { Non-CIM }\end{array}$ & 26 & 15 & 26 & 14 & 23 & 11 \\
\hline
\end{tabular}

Abbreviations:

QLQ-C30: Quality of Life Questionnaire-Core 30, QLQ-BR23: Quality of Life Questionnaire-Breast 23

Table 3: Hormones level per group and per visit

“*” indicates a significant difference $(p \leq 0.05)$ between CIM and non-CIM patients.

\begin{tabular}{|c|c|c|c|c|c|c|}
\hline \multirow[t]{2}{*}{ Hormones } & \multicolumn{3}{|c|}{ Inclusion (V0) } & \multicolumn{3}{|c|}{ End of chemotherapy (V1) } \\
\hline & $\begin{array}{c}\text { CIM [range] } \\
\text { (N) }\end{array}$ & $\begin{array}{c}\text { Non-CIM [range] } \\
\text { (N) }\end{array}$ & $p$ & $\begin{array}{l}\text { CIM [range] } \\
\text { (N) }\end{array}$ & $\begin{array}{c}\text { Non-CIM [range] } \\
\text { (N) }\end{array}$ & $p$ \\
\hline $\begin{array}{c}\text { AMH } \\
\text { (pmol/L) }\end{array}$ & $\begin{array}{c}3,93[0,1 ; \\
58,1](N=40)\end{array}$ & $\begin{array}{c}13,5[1,64 ; 69] \\
(N=17)\end{array}$ & *0.0032 & $\begin{array}{c}0,1[0 ; 0] \\
(\mathrm{N}=39)\end{array}$ & $\begin{array}{c}0,1[0,1 ; 1,21] \\
(N=15)\end{array}$ & 0.26 \\
\hline FSH (UI/L) & $\begin{array}{c}5,7[1,2 ; 65] \\
(N=39)\end{array}$ & $\begin{array}{c}4,5[1,5 ; 9,5] \\
(N=15)\end{array}$ & 0.07 & $\begin{array}{l}91,1[16,7 ; \\
198](N=28)\end{array}$ & $\begin{array}{c}83[11 ; 117] \\
(N=12)\end{array}$ & 0.47 \\
\hline $\begin{array}{l}\text { Estradiol } \\
\text { (pmol/L) }\end{array}$ & $\begin{array}{c}327[18,4 ; \\
1527](N=39)\end{array}$ & $\begin{array}{c}288[131 ; 782] \\
\quad(N=15)\end{array}$ & 0.49 & $\begin{array}{c}40[0 ; 495] \\
(\mathrm{N}=28)\end{array}$ & $\begin{array}{c}24,5[5 ; 1073] \\
\quad(N=12)\end{array}$ & 0.94 \\
\hline
\end{tabular}

Abbreviations:

AMH: Anti-Müllerian Hormon; FSH: Follicle Stimulating Hormone 


\section{FIGURE CAPTIONS}

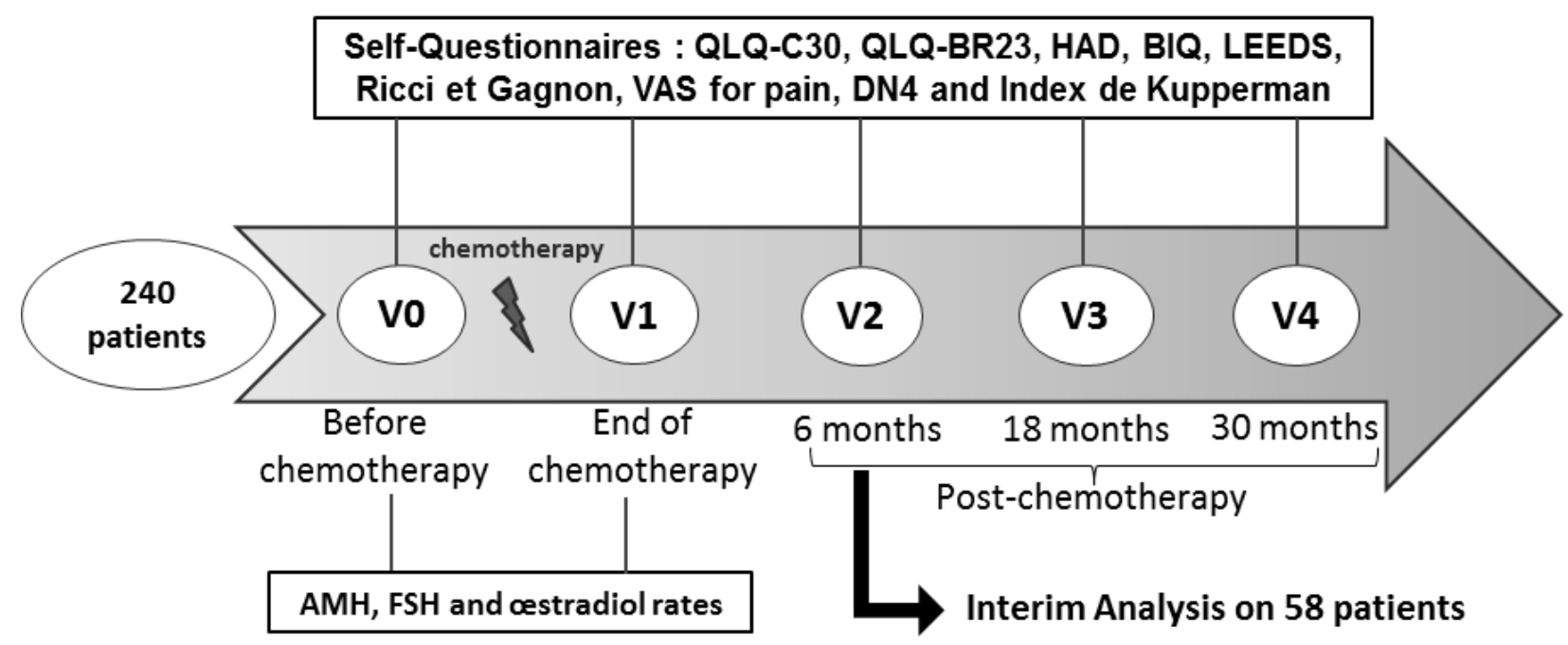

Fig.1. Study design

A total of 240 patients are expected to participate in this study and the interim analysis was conducted on 58 patients. To assess quality of life, patients were asked to complete the questionnaires several times: at inclusion before chemotherapy (V0), at the end of chemotherapy (V1), 6 months post-chemotherapy (V2), 18 months post-chemotherapy (V3) and 30 months postchemotherapy (V4). Hormonal measurements (AMH, FSH and estradiol) were done before chemotherapy (V0) and at the end of chemotherapy (V1).

Abbreviations:

AMH: Anti-Müllerian Hormone, BIQ: Body Image Questionnaire, DN4: Neuropatic pain in 4 questions, FSH: Follicle Stimulating Hormone, HAD: Hospital Anxiety Depression scale, LEEDS: sleeping quality questionnaire, QLQ-BR23: Quality of Life Questionnaire-Breast 23, QLQ-C30: Quality of Life Questionnaire-Core 30, VAS: Visual Analogue Scale 


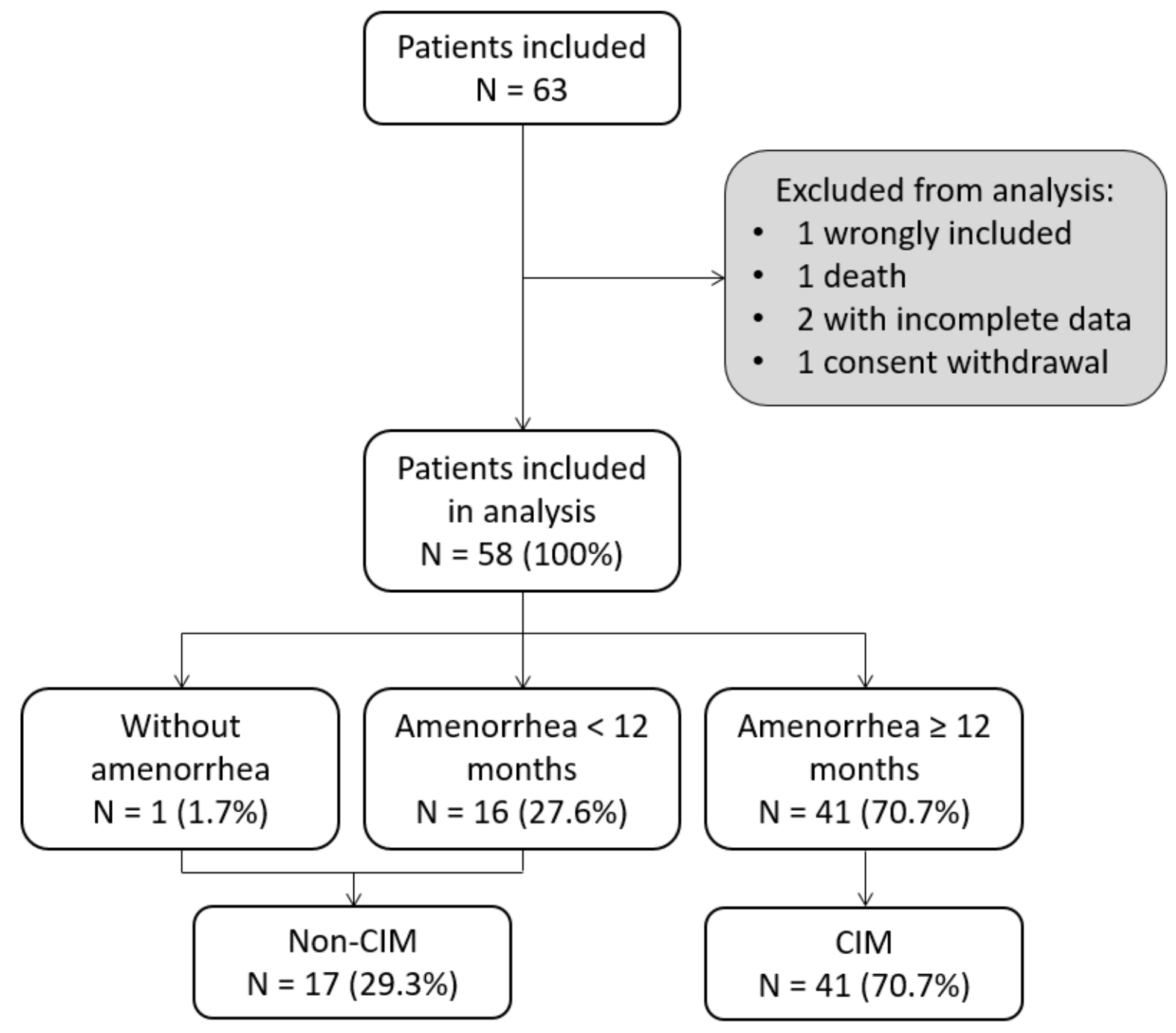

Fig.2. Flowchart of participants

Abbreviation:

CIM: Chemotherapy-Induced Menopause 


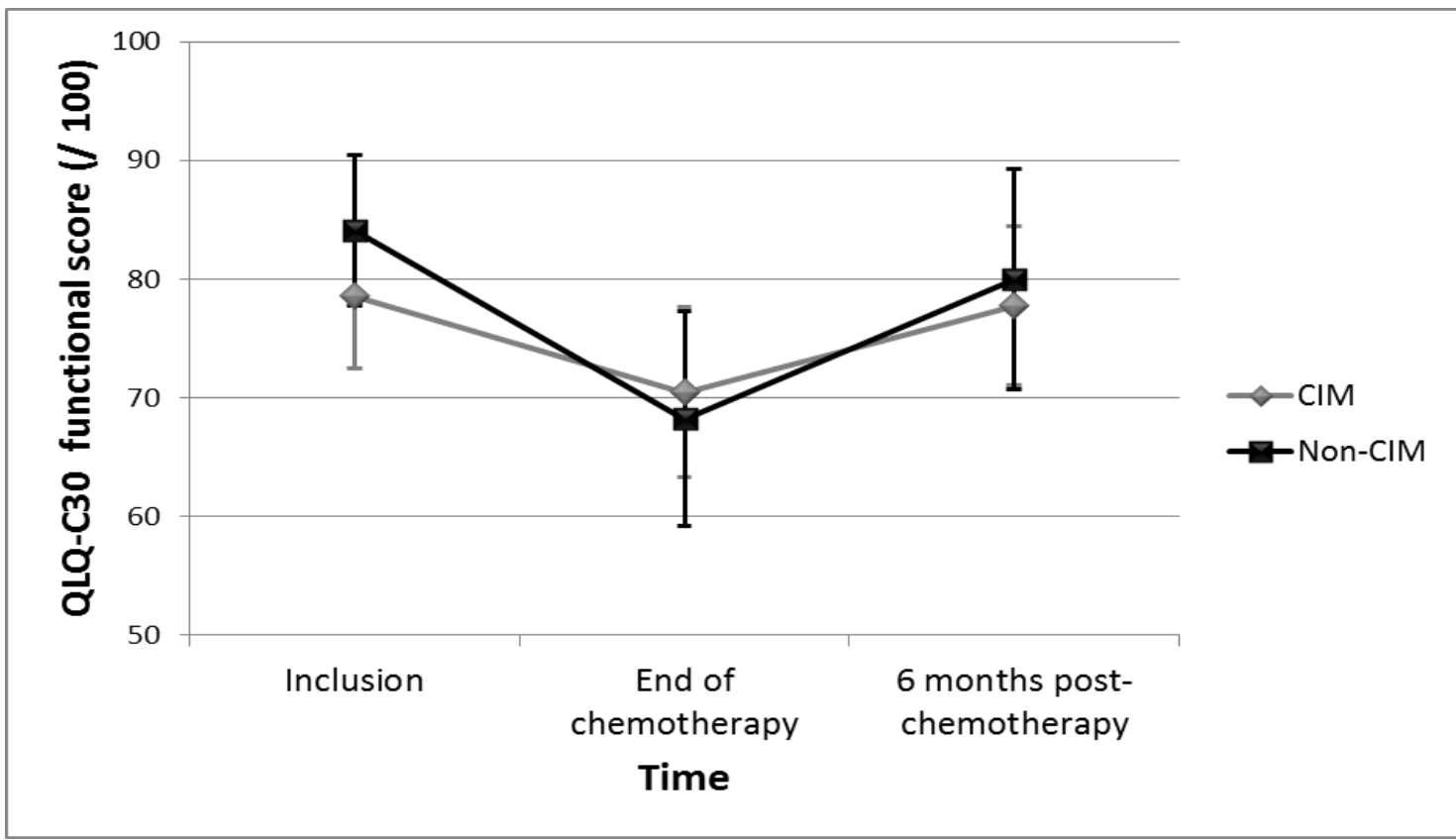

a. QLQ-C30 functional score variation from inclusion to 6 months post-chemotherapy: mean ( $\pm 95 \%$ confidence intervals).

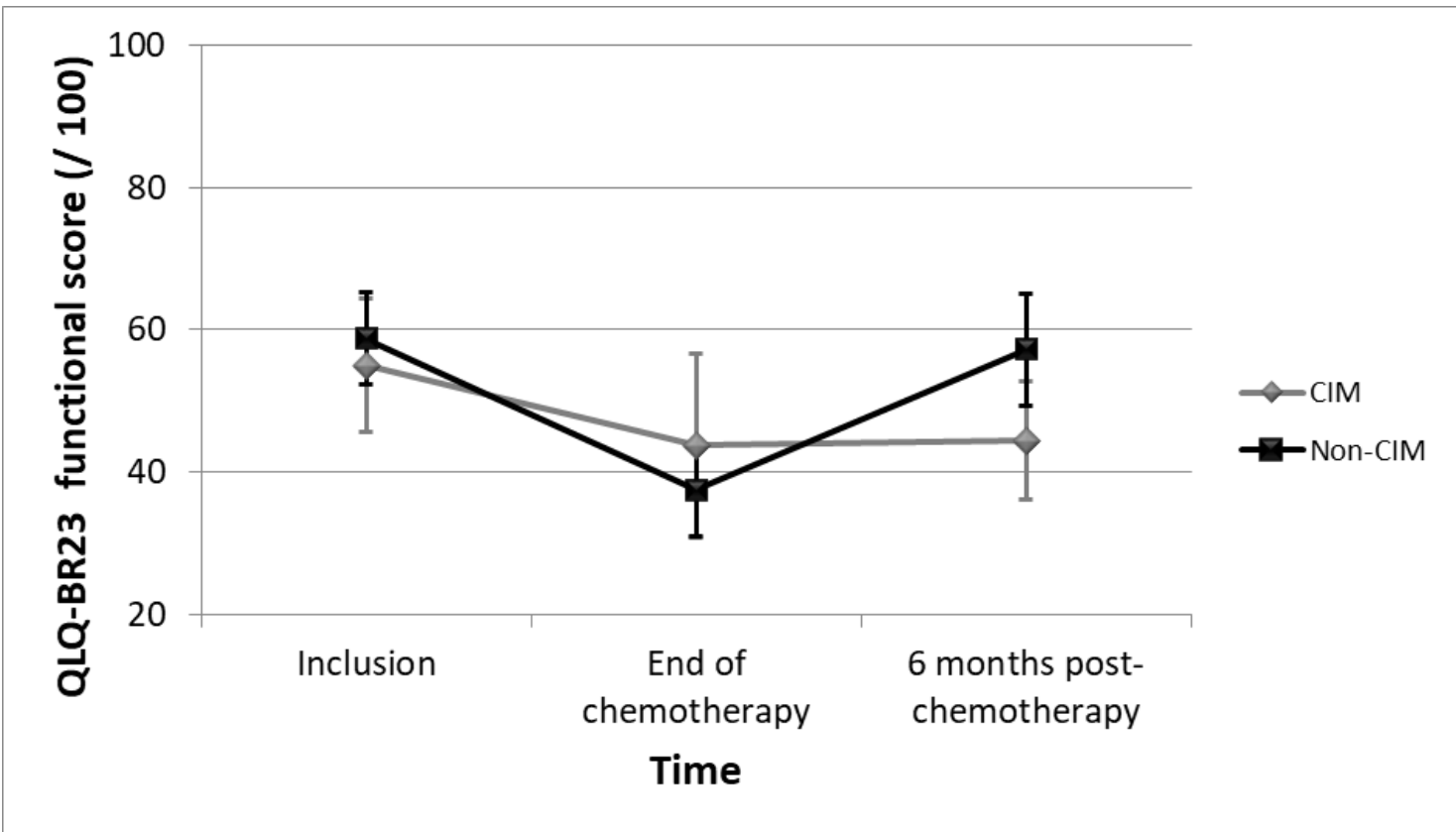

b. QLQ-BR23 functional score variation from inclusion to 6 months post-chemotherapy: mean ( $\pm 95 \%$ confidence intervals). 


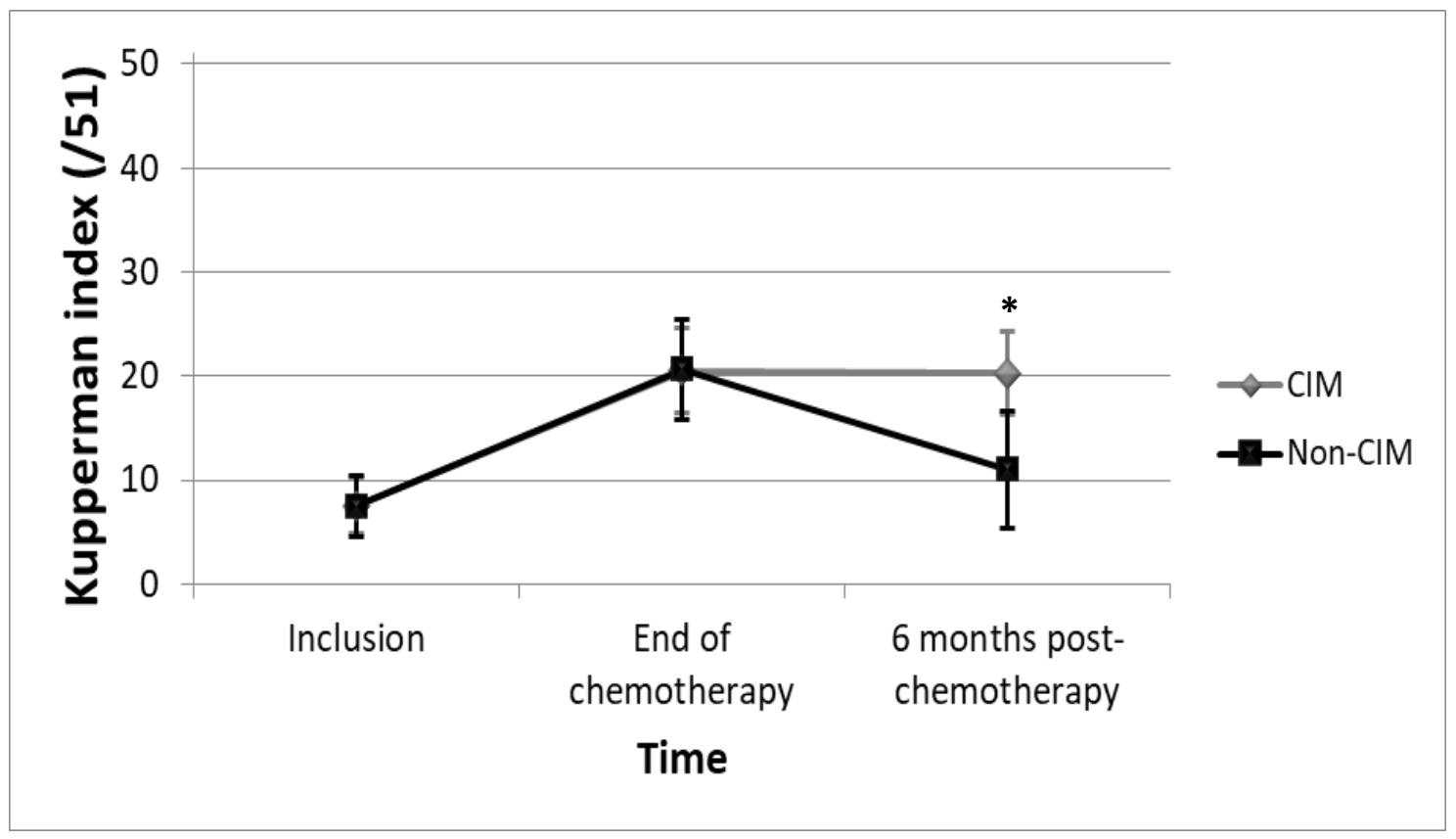

c. Kupperman index variation from inclusion to 6 months post-chemotherapy: mean $( \pm 95 \%$ confidence intervals).

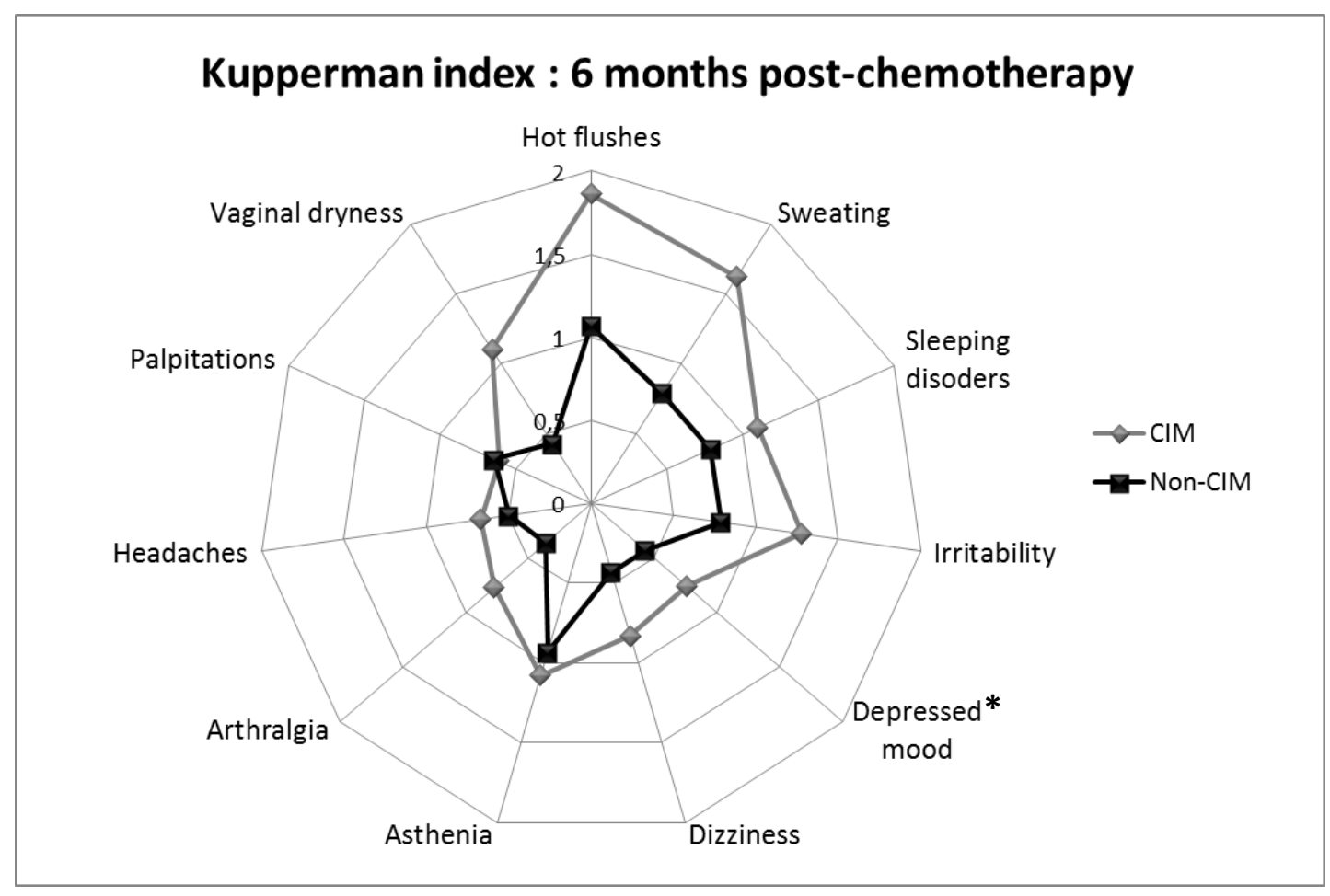

d. Analysis per dimension of Kupperman index at 6 months post-chemotherapy

Fig.3. Quality of life measurements: QLQ-C30 functional score variations between inclusion to 6 months post-chemotherapy (a.), QLQ-BR23 functional score variations between inclusion to 6 months post-chemotherapy (b.), Kupperman index variations between inclusion to 6 months postchemotherapy (c.) and analysis per dimension of Kupperman index at 6 months pots-chemotherapy (d.). " ** indicates a significant difference $(p \leq 0.05)$ between CIM and non-CIM patients. 


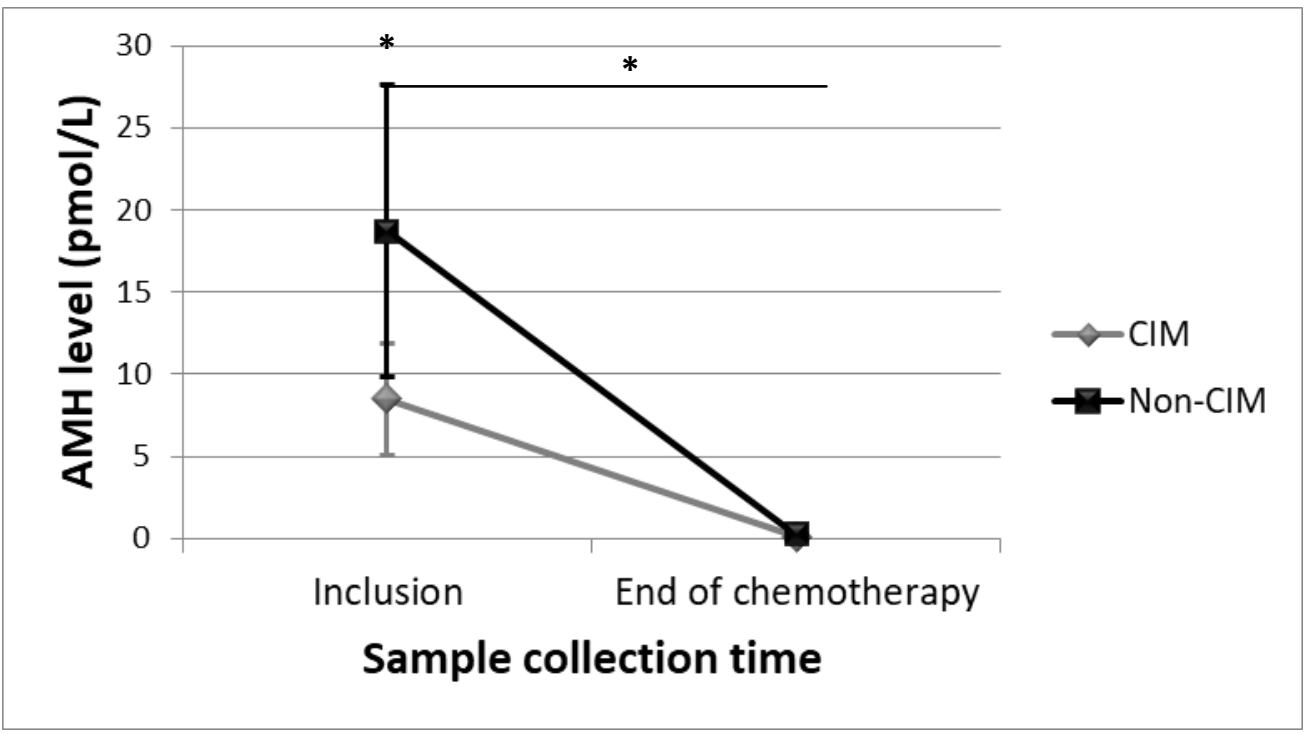

a. $\mathrm{AMH}$ serum level variation between inclusion and the end of chemotherapy: mean $( \pm 95 \%$ confidence intervals)

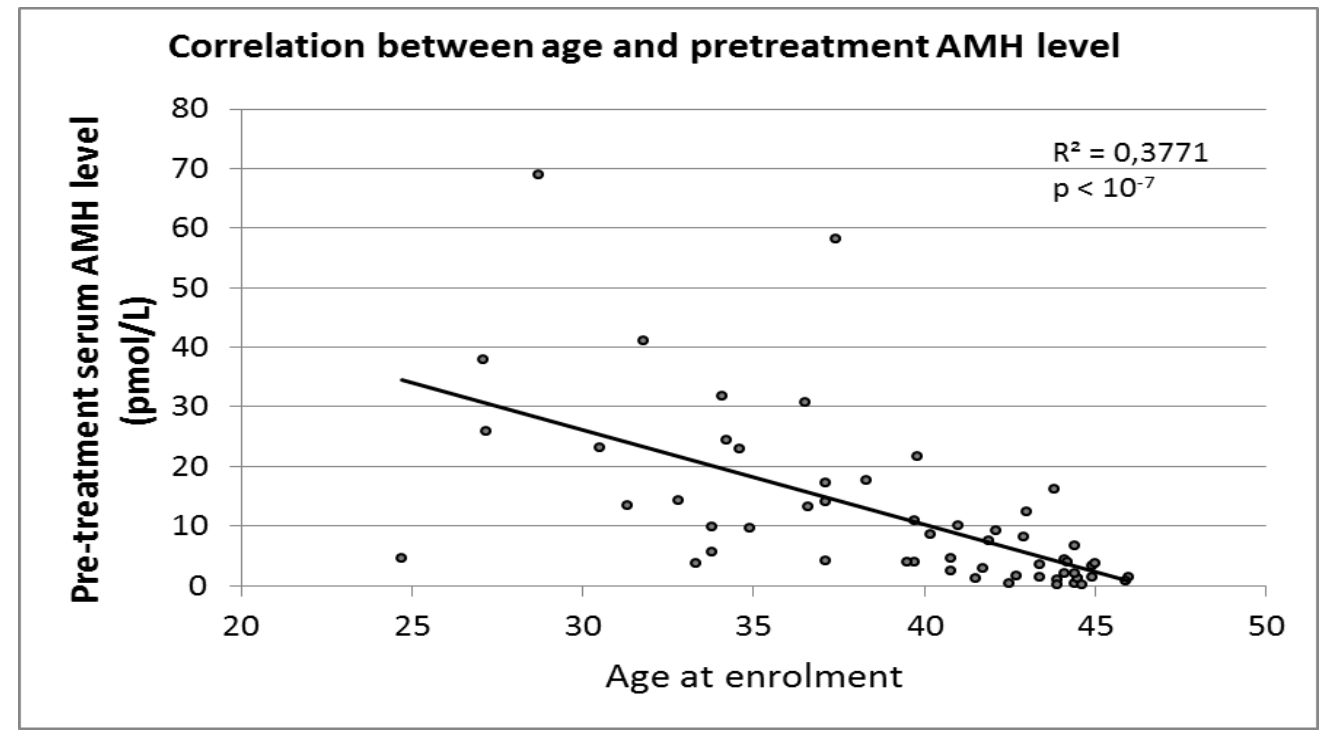

b. Correlation between patient's age and their pre-treatment AMH level

Fig.4. Hormone measurements: $A M H$ serum level variations between inclusion and the end of chemotherapy (а.) and Correlation between patient's age and their pre-treatment AMH level (b.). "*" indicates a significant difference ( $p \leq 0.05)$ between CIM and non-CIM patients. 